\title{
Stadt- und Regionalplanung
}

Herausgegeben von P. Koller und J. Diederich

Die Um- und Neugestaltung von Gebieten -

welche den Wohnstätten, Arbeitsplätzen, gemeinschaftlichen und kulturellen Betätigungen, Erholungsmöglichkeiten, aber auch den soziaien Versorgungen und der Aufgabenerfüllung der Planungsträger und Gebietskörperschaften dienen -

wird in unserer pluralen Gesellschaft mit ihren neuartigen Siedlungsformen und wachsenden Verkehrsbedürfnissen zu einer immer komplexeren Aufgabe.

Um diese Leistung von Ordnung und Planung im Raume gesellschaftsbezogen vollbringen zu können, sind in dieser Schriftenreihe Studien zur Methode und Analyse zusammengetragen. 



\section{Dichte und Mischung der Bevölkerung}

Raumrelevante Aspekte des Sozialverhaltens

von

Peter Atteslander

unter Mitarbeit von

Klaus Baumgartner, Frank Hollihn,

Walter Zingg, Gisela Zipp

$W$
DE
$G$

Walter de Gruyter - Berlin · New York 1975 
Dr. Peter Atteslander

o. Professor für Soziologie an der

Universität Augsburg

(c) Copyright 1974 by Walter de Gruyter \& Co., vormals G. J. Göschen'sche Verlagshandlung, J. Guttentag, Verlagsbuchhandlung Georg Reimer, Karl J. Trübner, Veit \& Comp., Berlin 30. Alle Rechte, insbesondere das Recht der Vervielfältigung und Verbreitung sowie der Ubersetzung, vorbehalten. Kein Teil des Werkes darf in irgendeiner Form (durch Fotokopie, Mikrofilm oder ein anderes Verfahren) ohne schriftliche Genehmigung des Verlages reproduziert oder unter Verwendung elektronischer Systeme verarbeitet, vervielfältigt oder verbreitet werden. -

Satz und Drudk: Oberbayerisches Volksblatt, Rosenheim. Bindearbeiten: Dieter Mikolai, Berlin. - Printed in Germany. 